\title{
Retrospective protocols: Tapping into the minds of interpreting trainees
}

The International Journal for Translation \& Interpreting Research trans-int.org
Marwa Shamy

Heriot-Watt University, UK ms491@hw.ac.uk

\author{
Raquel de Pedro Ricoy \\ Heriot-Watt University, UK \\ R.DePedro@hw.ac.uk
}

DOI: 10.12807/ti.109201.2017.a05

\begin{abstract}
Interpreting Studies has witnessed a growing interest in language specificity and its role in cognitive processing during simultaneous interpreting. The aim of this study is to establish trainee-interpreters' perceptions of language-pair-specific difficulties when working from English into Arabic in simultaneous mode. Fifteen postgraduate interpreting students were asked to perform two simultaneous interpreting tasks, into which language-pair-specific problem triggers had been incorporated. Process data was generated by applying the method of retrospection, the objective of which was to ascertain whether the problem triggers were perceived by the participants as such, and to identify the strategies, if any, that they employed to deal with them. Subsequently, a comparison was drawn between the perceptions that the participants verbalized and their actual performances.

Although the limitations of the method will be acknowledged, the use of retrospection yielded interesting data that can help enhance language-specific interpreter training. This approach is particularly innovative in the context of the language combination English-Arabic, which has received little scholarly attention to date. The information that can be gleaned from the application of the method can contribute to process-oriented research in interpreting pedagogy: "tapping into the minds" of trainee interpreters can help researchers and educators determine the factors that encumber students' performances and gain a better understanding of the development of strategic competence.
\end{abstract}

Keywords: Simultaneous interpreting, retrospection, interpreting pedagogy, Arabic, language-pair specificity, problem triggers

\section{Introduction}

Investigating unobservable mental processes has long been a challenge for researchers of different fields of study. One method which has been employed in various disciplines, such as psychology, cognitive science and second language acquisition, to gain at least partial insight into underlying cognitive processes, is introspection. It entails eliciting verbal reports from subjects by instructing them to verbalize thoughts occurring during performance of a specific task. There are two main types of introspection which are distinguished from each other by the temporal distance between action and verbalization (Færch \& Kasper, 1987, p. 15). Concurrent verbalization 
involves "externalising the contents of our minds as we engage in a particular activity" (Mann, 1982, p. 87). This technique, also called "thinking aloud", has been widely used by Translation Studies scholars to extract information on mental processes at play during translation (see Jääskeläinen, 2002 for a bibliography of think-aloud studies). Thinking aloud presupposes "that the modality of language use is not itself oral-productive" (Færch \& Kasper, 1987 , p. 15). Hence, its usage is by definition precluded in the interpreting field. Interpreting scholars have to avail themselves of retrospection instead, which involves reporting on thought processes after performing a task.

The aim of this article is to expand on existing knowledge in the field of Interpreting Studies and break new ground by illustrating how retrospective protocols can be triangulated with product-analysis methods to inform pedagogical practices. The research is based on an innovative study that centred on simultaneous interpreting from English into Arabic, a language combination that, in spite of its importance in the current socio-political climate, remains understudied. It will give an overview of the method of retrospection, its limitations and how it has been applied in Interpreting Studies. This will be followed by a description of the abovementioned study, which relied on the method of retrospection to ascertain what went through the minds of a group of trainees when confronted with language-pair-specific problem triggers that they had faced during a previous interpreting exercise. The findings derived from the data analysis will show the type of information that can be obtained through retrospection and how combining productoriented and process-oriented research methods can offset its limitations as a method.

\section{Retrospection}

According to Ericsson \& Simon (1993), retrospection builds on the assumption that a subset of the thought sequences occurring during a specific activity is stored in the long-term memory. If a retrospective report is generated immediately after completion of the task, there will be retrieval cues remaining in the short-term memory (Ericsson \& Simon, 1993, p. 149). To reactivate those traces in the short-term memory it is advised to use a cueing stimulus, preferably one which is "encoded in the same way at recall as it was at the original presentation" (Ericsson \& Simon, 1993, p. 119). Retrieval cues not only facilitate recall, but they also "counteract informants' tendency to conflate different events or confound them in retrospect" (Færch \& Kasper, 1987, p. 17). Using cueing stimuli and giving the participants general instructions to report their thoughts during the immediately preceding cognitive activity should produce verbal reports which to a large extent mirror the actual mental processes (Ericsson \& Simon, 1987, p. 41).

\subsection{Application of retrospection to research in simultaneous interpreting}

Simultaneous interpreting researchers have resorted to retrospection to examine a number of aspects: expertise components and skill variation between professionals and novices (Ivanova, 1999; Tiselius \& Jenset, 2011; Vik-Tuovinen, 2002), omissions by sign-language interpreters (Napier, 2004), directionality and strategy use (Bartłomiejczyk, 2006; Chang \& Schallert, 2007) and differences between retrospective reporting in translation and interpreting (Dimitrova \& Tiselius, 2009). The information gleaned from this investigative approach contributed to elucidating some cognitive aspects of 
simultaneous interpreting or at least served as a basis for hypothesis formation (Kohn \& Kalina, 1996, p. 133).

The abovementioned process-oriented researchers have employed different retrospection procedures. First, there are differences in the choice of cues which were used as prompts to the participants' memory. In retrospection after a simultaneous interpreting task recall can be aided by presenting the participants with the recorded source speech or a transcript thereof or the source speech in conjunction with the target speech. Ivanova (2000) undertook a small-scale pilot study and concluded that presentation of the original stimuli together with observational notes is the more effective procedure. It allows the verification of the protocols by comparing them with the participants' interpreting output and it reduces the risk of participants inferring "what they may or must have thought" (Ivanova, 2000, p. 33). Additionally, it spares the participants any embarrassment resulting from flaws in the target speech (Ivanova, 2000, p. 33). Dimitrova \& Tiselius (2009) and Tiselius \& Jenset (2011) followed Ivanova's procedure, while other researchers (e.g. Bartłomiejczyk, 2006; Chang \& Schallert, 2007; Vik-Tuovinen, 2002) opted for confronting the participants with the target speech. The latter approach might produce more data, but the protocols obtained might be tainted by the participants' urge to comment on or justify their interpreting decisions (Dimitrova \& Tiselius, 2009, p. 112).

Second, there are differences regarding the researcher's role during the verbalization process. Færch \& Kasper (1987) differentiate between "selfinitiated" and "other-initiated" retrospection (p. 17). Most studies in simultaneous interpreting are self-initiated with minimal interference by the researcher. Participants would listen to the dual-track recording of source and target text and stop the tape whenever they wish to make a retrospective remark (Bartłomiejczyk, 2006; Chang \& Schallert, 2007; Vik-Tuovinen, 2002) or they would go through the ST transcript and verbalize what came through their mind when interpreting the respective segment (Dimitrova \& Tiselius, 2009; Tiselius \& Jenset, 2011). In other-initiated retrospection participants only verbalize "when explicitly requested to do so by the experimenter" (Færch \& Kasper, 1987, p. 17). What Napier (2004) referred to as "task review" (p. 128) would fall into this category of retrospection. In Napier's study (2004) the researcher watched the videotaped interpreting task with the participant and asked them to comment on the instances of omission and provide a rationale for their behaviour. Thus, the verbalization process was steered by the experimenter who posed specific questions instead of giving general instructions. At this juncture it might be worth noting that there is no unified terminology in the literature, when it comes to the method of retrospection. Chang \& Schallert (2007), for instance, describe their experiment as a "retrospective interview" (p. 149), although it is self-initiated and does not follow the question-answer format typical of an interview. Moreover, in some cases the term "retrospective" does not reflect a strict application of the method of retrospection; it is rather used in the more general sense of "post-interpreting". Ribas (2012), for instance, examines problems and strategies in consecutive interpreting and indicates in her theoretical framework that she is applying the method of retrospection. However, the "retrospective questionnaire" she uses is not aimed solely at reconstructing mental processes occurring during the interpreting task. It also includes a question related to the participants' previous knowledge of the topic (p. 835). Similarly, Napier (2004) conducts what she calls "retrospective interview" (p. 129) after the abovementioned task review. The interview entailed using 
pre-set focus questions which address the interpreters' perception of the task. In the retrospective interview Napier $(2004$, p. 129) also goes beyond asking the participants to recall mental processes and asks them to identify any personal skills or knowledge which might have facilitated the interpreting assignment.

\subsection{Limitations of retrospection as a research method}

In spite of the fact that retrospective protocols have the potential of yielding interesting data, there are certain constraints which may have deleterious effects on the reliability of this method.

One limitation is related to the completeness of the elicited data. Since participants are asked to articulate thoughts that went through their minds during the interpretation task, subconscious decision making and automated cognitive processes are excluded by default (Ivanova, 2000, p. 28; VikTuovinen, 2002, p. 63). Verbalization is thus confined to conscious processes, which due to the time delay in retrospection are retrieved from the long-term memory. As such, they are subject to being forgotten (Vik-Tuovinen, 2002, p. 63). The incompleteness of data is not ascribed only to the time delay, since it is also a characteristic of think-aloud-protocols: Hansen (2005) claims that "the verbal report of a subject comprises only a fraction of all the thoughts during a process and only those that the subject can single out and encode into verbal form" (Hansen, 2005, p. 516). Hence, regardless of whether the verbal reporting happens concurrently or retrospectively, a complete recall of cognitive processes is beyond the bounds of possibility. The incompleteness of data is not necessarily a drawback. Krings (1987), for instance, regards the inaccessibility of unconscious processes to verbalization as a "desirable effect" (p. 167), since it allows researchers to distinguish between automated and non-automated processes.

There are also considerations pertaining to the accuracy of the information obtained through retrospective protocols. The time lag does not allow an unaltered retrieval of thought processes. In the act of verbalization mental structures undergo processes such as abstraction, generalization, elaboration and rationalization (Dimitrova \& Tiselius, 2009, p. 110; Hansen, 2005 , p. 519). Hansen (2005, p. 516) argues that individual experiences, prior knowledge, memories and emotions are also involved in a retrospective verbal report. This is due to the fact that our past experiences are stored as "dispositional patterns with an emotional content" which in new settings "automatically evoke associations and images" (Hansen, 2005, p. 515-516). Drawing on Damasio's (1994) findings in the field of neuropsychology, Hansen contends that it seems unlikely that a person be able to set aside thoughts from earlier experiences (Hansen, 2005, p. 516). Part of the onus is on the researcher, as the level and nature of intervention on his/her part affects the verbal report. His/her instructions might lead the participant to infer information rather than to merely retrieve it (Ivanova, 2000, p. 28). As mentioned above, the choice of retrieval cues may also influence the degree of distortion. There is another responsibility which lies with the researcher, namely that of faithfully reconstructing the meaning intended by the participant (Ivanova, 2000, p. 28). The analysis process could further modify the data which is already inherently indirect:

And in all cases, however directly the process may be expressed, we are at least two steps away from the actual phenomenon we wish to observe and we are likely to lose or gain data as it passes from the subject's mind to the protocol, 
from the protocol to the analyst's mind, and from the analyst to the presentation of the analysis. (Mann, 1982, p. 95)

When applying the method of retrospection, it is also important to factor in personal and interpersonal determinants. Individual variations in the reports can be attributed to personality differences and the ability to deal with the novelty of the task in the absence of pre-training (Ivanova, 2000, p. 28). The relationship between the researcher and the participant could also influence the level of verbosity: participants might be more inclined to give comments if they know the researcher (Vik-Tuovinen, 2002, p. 65). Mann (1982) emphasizes that the data collection process is a social situation governed by interpersonal dynamics. Participants may feel "unsure of themselves" or "threatened by the feeling of inferiority" (Mann, 1982, p. 93). The fact that they cannot assess the value of their contribution might lead them to "overcompensate" or even to mislead in the desire to be "good" subjects (Mann, 1982, p. 89, 94). They might also react by being "reticent" or "uncooperative" (Mann, 1982, p. 93). The researcher, on the other hand, may be "anxious, over-demanding, biased, impatient and over-suggestive" (Mann, 1982, p. 93). A way of minimising these potential drawbacks is to allow the respondents to work independently, in a booth, for instance, or without the researcher being present in the room. However, this adaptation to the method also has disadvantages, in that the researcher effectively relinquishes control over how the reflection is conducted and verbalized.

In view of these limitations, the method of retrospection has attracted some criticism. Seeber (2013), for instance, argues that retrospection, being categorized as a subjective method, "might not provide the necessary objectivity to reliably assess cognitive load in simultaneous interpreting" (p. 23). He noted that the limitations of the method led Shlesinger (2000) to conclude that "for all intents and purposes, TAPs, in the ordinary sense, are not a viable tool for us" (p. 3). It must be noted, however, that this citation was taken out of context, as Shlesinger was referring to concurrent probing, which, as mentioned above, cannot be applied to simultaneous interpreting data.

The limitations of retrospection cannot be disregarded and scholars should be aware that relying solely on retrospective protocols might not lead to claims of generalizable value. However, rather than discarding the method as a valid investigative tool, researchers can resort to it to supply complementary data as part of a mixed-method approach, as was advocated by Kohn \& Kalina (1996, p. 133). Combining retrospection with other research methods, such as product-oriented methods, allows for it to be validated and can compensate for its inherent shortcomings (Bartłomiejczyk, 2006, p. 128; Dimitrova \& Tiselius, 2009).

The study presented in the following section relied on retrospection to elicit secondary process data which would help inform the primary product data. The veridicality of the reports can be discerned through comparing the reports with the actual interpreting output of the participants.

\section{Methodology}

This section will explain how the correlation between product data and process data in relation to language-pair-specific difficulties was examined. A study was conducted by one of the co-authors (henceforth, "the researcher"), focusing on "problem triggers" (Gile, 1995/2009, p. 192), which derive from the structural differences between the language pair English-Arabic. It is 
grounded on the growing interest within Interpreting Studies in language specificity and its role in cognitive processing during simultaneous interpreting. A number of studies investigated language-specific problem triggers and explored the strategies that can be used to handle them (see AlRubai'i, 2004; Donato, 2003; Kurz, 1983; Ross, 1997; Shakir \& Farghal, 1997; Uchiyama, 1991). The interest in language specificity is also manifested in the increasing consideration given to the topic of directionality: a special "Directionality Research Group" was created at the University of Bologna in 2004, and various studies examined the connection between directionality and strategies in different language pairs and language directions (see Bartłomiejczyk, 2006, Chang \& Schallert, 2007).

The study consisted of two parts. In part I, participants were asked to perform two simultaneous interpreting tasks from English into Arabic. The product data obtained were used to examine how the participants dealt with the language-pair-specific problem triggers which were embedded in the source texts. In part II, process data were generated by applying the method of retrospection, the aim of which was to ascertain whether the incorporated problem triggers were perceived by the participants as such, and to identify the strategies they employed, if any, to deal with them. This second part will be the focus of this paper, as it is particularly interesting to elucidate the mental processes at play when interpreting trainees are faced with factors which are likely to engender cognitive load.

The participants, the input material and the procedure used to generate and analyse the retrospective protocols will be presented below. This will be followed by a discussion of the findings that reflects the type of information that was obtained by using the method of retrospection and how they can contribute to enhancing pedagogical practices. The validity of the method will be determined based on a comparison between the product data and process data.

\subsection{Participants}

The target population for this study were native speakers of Arabic who had just completed or were in the final stage of a Master's degree in Conference Interpreting English-Arabic. They were expected to have acquired the basic interpreting skills (such as attention splitting or ear-voice-span management) and would be able to assign some cognitive capacity to dealing with the incorporated problem triggers.

Due to the qualitative nature of the study, a non-probabilistic sampling method was employed. At the time of data collection, the researcher was teaching the English-Arabic conference interpreting cohort at Heriot-Watt University and thus had direct access to potential participants. Contact was established with all other UK universities that offered English-Arabic conference interpreting courses at Master's level, which were expected to have students with the required characteristics. These were the University of Salford and the University of Central Lancashire. A total of 15 participants were willing to participate in the study: 6 from Heriot-Watt University, 6 from the University of Salford and 4 from the University of Central Lancashire.

The sample consists of 6 female and 9 male interpreters whose ages range between 25 and 58. The group is fairly heterogeneous in terms of country of origin. Out of the 15 participants, 2 are from Egypt, 2 from Syria, 2 from Saudi Arabia, 2 from Algeria, 2 from Morocco, 1 from Libya, 1 from Palestine, 1 from Iraq, 1 from Jordan and 1 from the United Arab Emirates. 


\subsection{Input material}

The participants were asked to interpret two texts from English into Arabic. The first one was a speech delivered in a real-life, interpreted context: an address on the Syrian crisis originally given by UN Secretary General Ban Kimoon to the General Assembly on August $3^{\text {rd }}$ 2012, which was customized to fit the purpose of the study. This customization entailed incorporating language-pair-specific problem triggers, on the one hand, and, on the other, simplifying a number of phrases in an attempt to minimize any comprehension problems. The length and duration of the speech (1024 words / 10:20 minutes) were appropriate for the research purposes. It is approximately the same length as students' final exam speeches. At this stage, students or fresh graduates have not yet built up the stamina to interpret for 20 or 30 minutes. So limiting the speech to 10 minutes was believed to minimise fatigue effects. The second speech was written by the researcher to simulate a comment made by a representative of the American government taking part at the meeting of the Working Group on Economic Recovery and Development of the Friends of the Syrian People, which actually took place in Berlin on September 4th, 2012. The rationale for using a second speech was to cover an example of semi-impromptu material (the speaker was using notes when delivering the speech) in addition to a speech that was written to be delivered orally. This allowed the researcher to incorporate linguistic structures which are more typical of spoken discourse. The speech was 3:05 minutes long (322 words). Both speeches were recorded by a native speaker of American English delivered at a pace of $104 \mathrm{wpm}$ which, according to Gerver (1971), can be deemed as fairly comfortable.

Seven language-pair-specific problem triggers were identified on the basis of a review of relevant literature in Interpreting Studies, Contrastive Translation Studies and Contrastive Linguistics and were embedded in the source texts. The problem triggers were categorized based on Merten's (1983, p. 101 et seq. ) typology of semiotic discourse levels as shown in Table 1.

Table 1: Problem triggers for the language pair English-Arabic categorized based on Merten's semiotic levels of discourse (translated version adopted from Titscher, Meyer, Wodak, \& Vetter, 2000, p. 61-62)

\begin{tabular}{|l|l|l|}
\hline Level of discourse & Object of analysis & $\begin{array}{l}\text { Language-pair-specific } \\
\text { problem trigger }\end{array}$ \\
\hline Syntactic level & $\begin{array}{l}\text { Letters, syllables, words or } \\
\text { sentences and their } \\
\text { structures, in so far as those } \\
\text { are purely formal }\end{array}$ & $\begin{array}{l}\text { Acronyms } \\
\text { Word order }\end{array}$ \\
\hline $\begin{array}{l}\text { Syntactic-pragmatic } \\
\text { level }\end{array}$ & $\begin{array}{l}\text { Influence of syntax in the } \\
\text { construction of meaning }\end{array}$ & $\begin{array}{l}\text { Passive constructions } \\
\text { Argumentation styles } \\
\text { Definite article as means of } \\
\text { emphasis }\end{array}$ \\
\hline $\begin{array}{l}\text { Semantic-pragmatic } \\
\text { level }\end{array}$ & $\begin{array}{l}\text { Relationship between } \\
\text { particular meaning-bearing } \\
\text { text units and textual effect }\end{array}$ & $\begin{array}{l}\text { Modals } \\
\text { Discourse markers }\end{array}$ \\
\hline
\end{tabular}

The considerable syntactic disparities between English and Arabic and the constraints characteristic of the simultaneous mode, namely the time constraint, the linearity constraint and the unshared knowledge constraint (Shlesinger, 1995, p. 194), can lead to an increase in the cognitive load during interpretation. In the case of acronyms, the difficulty lies in the fact that they 
are a rarely used phenomenon in Arabic (Al-Qinai, 2007, p. 368). In most cases, when relaying acronyms from English, every component of that acronym needs to be spelled out. This has implications on processing time and effort in simultaneous interpreting. As for word order, there are certain patterns that force the English-Arabic interpreter to lag behind the speaker for a time that exceeds 3 seconds until a certain key word is revealed, thus potentially leading to a short-term memory overload (Al-Rubai'i, 2004, p. 249).

At the syntactic-pragmatic level, interpreters might encounter difficulties in relaying passive constructions, as they are dispreferred in Arabic. The norm is to transpose them into active sentences (Cantarino, 1975, p. 53; Khalil, 1993, p. 169). This entails structural adjustments that are difficult to make due to limited time and processing capacity. Regarding argumentation styles, the difficulty lies in relaying counter-argumentative structures from English into Arabic, as Arabic displays a preference for through-argumentation. The difficulty is attributed, inter alia, to the fact that some of the signals indexing one of the argumentation styles perform very different text-typological functions in English and in Arabic (Hatim, 1997, p. 212). Finally, the use of the phonemic variation /ði:/ of the English definite article for emphasis constitutes a language-pair-specific problem trigger, since in Arabic the definite article is expressed through the proclitic /'al/, which cannot receive different levels of stress (Hawas, 1989, p. 25).

At the semantic-pragmatic level, interpreting modal expressions from English into Arabic can pose a challenge due to the significant formal divergence in the way modality is expressed in the two languages, as "modality in Arabic is not associated with a distinct, unitary formal category, but rather is expressed by means of a heterogeneous set of categories" (Eades, 2011, p. 283). As for discourse markers, Arabic tends to use a limited number of markers, each of which covers a broad semantic range (Baker, 1992, p. 193), while English uses a wider array of discourse markers, as demonstrated in the highly nuanced taxonomy developed by Halliday \& Hasan (1976). English- into-Arabic interpreters may encounter problems resulting from lack of familiarity with the meaning relations expressed by English markers and the multitude of functions that Arabic discourse markers can perform. Other problems may arise from the constraints associated to the simultaneous mode and effort-management.

\subsection{Retrospective protocols}

\subsubsection{Procedure}

Immediately after both interpreting tasks were completed, the method of retrospection was employed to generate process data. As mentioned above, interpersonal dynamics between researcher and participants could potentially affect the outcome of this method and need therefore to be taken into account. Heriot-Watt students who participated in the study were already familiar with the researcher, as she was their conference interpreting instructor. For the sake of academic rigour, and to allay any fears among the participants that they may be evaluated, the study was carried out after their final exams. As for the participants from the University of Salford and the University of Central Lancashire, it was deemed appropriate to visit both universities prior to conducting the study to build rapport with the students and explain what the study would entail. 
In the attempt to obtain verbal data that yield the closest approximation to actual thought processes, the video recording of the source speeches that was shown to the participants during the interpretation task was used as a retrieval cue. As stated above, not providing the participants with the target text reduces the risk of inferring, spares them any embarrassments and allows for verification of the protocols by comparing them to the interpreted output. The participants were given a set of instructions that were incorporated into a conversation, rather than read out, to put the participants at ease and to allow them to react and ask questions. The instructions included a statement of the purpose of the exercise and an explanation of the procedure. Participants were also given reassurance that there was no right or wrong answer and that it would be normal if they did not remember what went through their minds during a particular segment. They were informed that the protocols would be recorded and that they would remain anonymous. There were no restrictions imposed on the participants as far as the language of verbalization is concerned. Most participants used a mixture of English and Arabic and all of them used their regional variety of the latter (Libyan, Palestinian, Syrian, etc.). Algerian students delivered their reports partly in French.

The verbalization process was largely self-initiated. The researcher only intervened to reply to direct questions, to seek clarification as a result of her unfamiliarity with the regional variety of Arabic used by the participant, or when participants failed to express themselves unambiguously. In cases where the researcher accidentally posed leading questions, the answers to such questions were excluded from the analysis. Participants' unfamiliarity with the task triggered some insecurity, which led a number of them to ask explicitly during the retrospection process whether their contributions were of any value. All participants were reassured that their remarks were of great value to the research project.

\subsubsection{Transcription}

All retrospective protocols were audio-recorded. The question that arose after the data collection process was whether to transcribe the audio recordings or conduct the analysis based on the oral data. Niemants (2012, p. 174-178) presents in some detail the arguments of proponents and opponents of transcription. Those in favour of transcribing (e.g. Gavioli \& Mansfield, 1990; Straniero Sergio, 1999) contend that the process helps preserve the data more permanently, promotes familiarity with the data and fosters methodological thinking (Niemants, 2012, p. 175). Transcription opponents (e.g. Szakos \& Glavitsch, 2004) regard the audio recordings as the only true data, since transcribing entails making interpretive choices (Niemants, 2012, p. 177).

It is important to bear in mind that transferring oral speech into the written format is a means to facilitate the analysis process, or "the researcher's 'seeing'", as Lapadat (2000, p. 214) puts it. In the study, the participants used regional varieties of Arabic in their retrospective protocols. These are used almost exclusively in the oral mode, and as such, they do not lend themselves easily to transcription. The transcriptions would thus be denaturalized by default. In addition, when it comes to retrospective reporting, supralinguistic features can indicate the level of certainty on the part of the participants and whether they are retrieving thoughts or inferring them. Even if transcripts that included as many oral features as possible were produced, they would be a poor substitute given the aim of the study, since they would lack the richness and nuance of the oral data. Consequently, it was decided that transcribing the protocols would hamper the analysis process, rather than facilitate it. 
The usage of regional varieties of Arabic in conjunction with other languages (English or French, as mentioned above) and the fact that a large amount of the data would not pertain to the purpose of the study led to the decision of only transcribing the extracts which are relevant to the analysis, so that they could be used for illustration purposes, as will be shown in the following section.

\subsection{Analysis}

The comments on the segments of the source speeches containing the language-pair-specific problem triggers were analysed based on six categories: problem $(\mathrm{P})$, actual strategies $(\mathrm{S})$, potential strategies $(\mathrm{pS})$, satisfaction (Sat), other difficulties (oD) and no comment (-). 'Problem' segments indicate that the participant recognized the problem trigger as such and described the problem that $\mathrm{s} / \mathrm{he}$ faced without providing a solution. 'Actual strategies' segments refer to comments related to decisions made or strategies used by the participant to deal with the problem trigger in question. 'Potential strategies' segments contain information on strategies that the participant believed $\mathrm{s} / \mathrm{he}$ should have employed, but did not. 'Satisfaction' segments are those in which a participant expresses his/her satisfaction with the way s/he handled the source text unit. In segments encoded as 'other difficulties' participants report on difficulties other than the language-pair-specific problem trigger that they had encountered. Within this category, it is important to establish causality and to ascertain whether flaws in the output or prosodic features associated to the cognitive load (such as voiced hesitations or pauses) are actually attributable to the problem trigger or to other factors. Table 2 provides illustrative examples from the reports for each of the categories and the abbreviations used for coding the data.

Table 2: Examples of the different categories of retrospective comments

\begin{tabular}{|l|l|l|}
\hline Category & Problem trigger & Comment \\
\hline Problem (P) & Definite article & $\begin{array}{l}\text { "The words were clear. Then I was thinking } \\
\text { how can I express the difference between a } \\
\text { chance and the chance" (translated from Syrian } \\
\text { Arabic). }\end{array}$ \\
\hline Strategy (S) & Acronyms & $\begin{array}{l}\text { "I heard the OCHA and I just ... my mind } \\
\text { (snapped his fingers) just triggered that the } \\
\text { word is in front of me in the glossary [...]. It } \\
\text { gave me a leeway to catch up with what was } \\
\text { coming" (original). }\end{array}$ \\
\hline $\begin{array}{l}\text { Potential } \\
\text { Strategy (pS) }\end{array}$ & Discourse marker & $\begin{array}{l}\text { "Here when she said 'after all I made a } \\
\text { mistake. I interpreted it literally and then } \\
\text { immediately I thought of the alternative I should } \\
\text { have opted for. I should not have started } \\
\text { interpreting right away. This was a mistake" } \\
\text { (translated from Palestinian Arabic). }\end{array}$ \\
\hline $\begin{array}{l}\text { Satisfaction } \\
\text { (Sat) }\end{array}$ & $\begin{array}{l}\text { "As far as I can remember this bit went well" } \\
\text { (translated from Egyptian Arabic). }\end{array}$ \\
\hline $\begin{array}{l}\text { Other } \\
\text { Difficulties (oD) }\end{array}$ & Word order & $\begin{array}{l}\text { "Here I felt that I was lost. The acronyms and } \\
\text { the other things. Because the last segment did } \\
\text { not go well, this segment was affected. Maybe } \\
\text { because I looked at the glossary and kept } \\
\text { searching so I missed what came after the } \\
\text { acronyms. I wasn't able to catch up" (translated } \\
\text { from Libyan Arabic). }\end{array}$ \\
\hline
\end{tabular}




\section{Results}

The results for each problem trigger will be presented in tables which show what type of comment was made by how many participants, and the number of participants who had appropriately dealt with the problem trigger in question (signalled by a check mark) and the number of those who had not (signalled by an $\mathrm{x}$ ). This will give an indication to whether the verbalizations were consistent with the actual behaviour. Illustrative examples of retrospective comments which fall into the categories of problem (P), actual strategies $(\mathrm{S})$ or potential strategies $(\mathrm{pS})$ will be given for each problem trigger.

\subsection{Acronyms}

Table 3: Correspondence between product and process data related to the problem trigger "acronyms"

\begin{tabular}{|l|l|l|l|l|l|l|l|l|l|l|l|l|l|l|l|l|l|l|}
\hline & $\mathrm{P}$ & $\checkmark$ & $\mathrm{x}$ & $\mathrm{S}$ & $\checkmark$ & $\mathrm{x}$ & $\mathrm{pS}$ & $\checkmark$ & $\mathrm{x}$ & Sat & $\checkmark$ & $\mathrm{x}$ & $\mathrm{oD}$ & $\checkmark$ & $\mathrm{x}$ & - & $\checkmark$ & $\mathrm{x}$ \\
\hline UNESCO & & & & 2 & 1 & 1 & & & & & & & 10 & 6 & 4 & 3 & 2 & 1 \\
\hline OCHA & 4 & 3 & 1 & 7 & 7 & & & & & & & & 3 & 3 & & 1 & & 1 \\
\hline OCHA & 1 & 1 & & 1 & 1 & & & & & 4 & 2 & 2 & 4 & 2 & 2 & 5 & 4 & 1 \\
\hline UNSMIS & 5 & & 5 & 3 & 3 & & 1 & & 1 & 1 & 1 & & 2 & 1 & 1 & 3 & 2 & 1 \\
\hline UNSMIS & 3 & & 3 & 2 & 2 & & & & & 1 & & 1 & 4 & 1 & 3 & 5 & 3 & 2 \\
\hline Total & $\mathbf{1 3}$ & $\mathbf{4}$ & $\mathbf{9}$ & $\mathbf{1 5}$ & $\mathbf{1 4}$ & $\mathbf{1}$ & $\mathbf{1}$ & & $\mathbf{1}$ & $\mathbf{6}$ & $\mathbf{3}$ & $\mathbf{3}$ & $\mathbf{2 3}$ & $\mathbf{1 3}$ & $\mathbf{1 0}$ & $\mathbf{1 7}$ & $\mathbf{1 1}$ & $\mathbf{6}$ \\
\hline
\end{tabular}

Table 4: Examples of comments related to the problem trigger "acronyms"

\begin{tabular}{|l|l|l|}
\hline Category & Participant & Comment \\
\hline $\begin{array}{l}\text { Problem } \\
\text { (P) }\end{array}$ & $\begin{array}{l}\text { (on } \\
\text { UNSMIS) }\end{array}$ & $\begin{array}{l}\text { "She said it as if it was composed of two separate parts: } \\
\text { UNS and MIS. I have to get used to what it sounds like" } \\
\text { (translated from Iraqi Arabic). }\end{array}$ \\
\hline $\begin{array}{l}\text { Strategy } \\
(\mathrm{S})\end{array}$ & $\begin{array}{l}3 \text { (on } \\
\text { OCHA) }\end{array}$ & $\begin{array}{l}\text { "When he said OCHA I read it out immediately so that I } \\
\text { don't think about it and waste time" (translated from } \\
\text { Egyptian Arabic). }\end{array}$ \\
\hline $\begin{array}{l}\text { Potential } \\
\text { Strategy } \\
\text { pS) }\end{array}$ & $\begin{array}{l}9 \text { (on } \\
\text { UNSMIS) }\end{array}$ & $\begin{array}{l}\text { "Maybe it would have been better if I took those four } \\
\text { acronyms and those three words and wrote them down at } \\
\text { the bottom of the page. Separated from the rest of the } \\
\text { glossary items and with space between them. I got lost } \\
\text { when they were among the other items. I thought of this } \\
\text { strategy after getting out of the booth, that I write them } \\
\text { down with space between them so that I can see them } \\
\text { more clearly" (translated from Libyan Arabic). }\end{array}$ \\
\hline
\end{tabular}

The Arabic translations of the acronyms were provided in a glossary that the participants were able to consult before and during the interpretation task. Out of 75 segments containing an acronym, 30 were not rendered appropriately. In 13 cases participants reported having faced difficulty in rendering the acronym into Arabic. A comparison between the retrospective comments and the textual output revealed that in 9 instances this was indeed the case. In the remaining 4 cases there is inconsistency between what was articulated by the participants and their behaviour in the booth. In the retrospective comments they indicated that they failed to render the acronyms, while their interpreting output shows that they were successful in relaying the problem-trigger. This suggests that their memory of the actual thought 
processes during the interpretation task was distorted, but that they recognized the acronym as a potential problem-trigger upon listening to the source text the second time.

In 15 cases, participants described a strategy they had employed to deal with the problem-trigger. With the exception of one participant, textual evidence demonstrated that the reported strategies were indeed adopted. One participant failed to interpret the acronym appropriately, but thought of a potential strategy during the retrospection session. In only half the cases where participants expressed satisfaction with their output were they actually successful in dealing with the problem trigger. Hence, the verbalization did not correspond to the product of the interpretation.

A high number of those who reported other difficulties in this textual unit or did not make any comment exhibited strategic behaviour and were able to deal with the acronyms ( 13 out of 23 and 11 out of 17 respectively). There are two possible explanations for why no direct references were made to the problem-trigger: either this strategic behaviour was automated, or the participants were unable to recall having made conscious cognitive effort. It could be also argued that the participants, not being expert professionals, were unable to oralize their thoughts; however, their verbalization behaviour in the case of other triggers seems to disprove this. As for the 16 participants who failed to deal with the acronyms and did not address the problem trigger in their retrospective remarks, their thought processes were either forgotten or they were not aware of the difficulty during the interpretation task.

\subsection{Word order}

Out of 135 segments that included problematic word order patterns, 47 were relayed correctly, while 88 renditions were grammatically incorrect. In a total of 20 cases, the retrospective comments referred to problems that participants had faced when interpreting those textual units. The level of awareness varied depending on the word order pattern in question. As shown in the table, premodification by adjectives was more easily recognizable as a problem trigger compared to other word order arrangements occurring in the source texts. In 6 cases participants were able to successfully deal with the problem trigger despite having reported difficulties during the interpretation task.

In 8 out of 10 cases where participants reported having made conscious strategic choices, there was textual evidence confirming their reports. Inconsistency between the retrospective comments and the output was detected in the category of 'satisfaction', as 7 out of 13 participants who reported being satisfied with their output did not employ the necessary strategies to relay the problem trigger.

40 out of the 58 participants whose comments fall into the category of 'other difficulties' and 25 out of the 34 who made no retrospective comment were not able to produce appropriate target language renditions. As was the case with acronyms, this might be attributed to failure to remember the difficulties they had encountered or lack of awareness of the difficulties during the interpretation task. Another reason might be that the problem trigger in this case is not a single lexical item as was the case with acronyms. It is one that affects the clause or sentence level. Participants might have found it harder to pinpoint the source of the difficulty or describe its nature. 
Table 5: Correspondence between product and process data related to the problem trigger "word order"

\begin{tabular}{|c|c|c|c|c|c|c|c|c|c|c|c|c|c|c|c|c|c|c|}
\hline & $P$ & $\checkmark$ & $x$ & $\mathrm{~S}$ & $\checkmark$ & $x$ & $\mathrm{pS}$ & $\checkmark$ & $x$ & Sat & $\checkmark$ & $x$ & $\mathrm{oD}$ & $\checkmark$ & $x$ & - & $\checkmark$ & $x$ \\
\hline $\begin{array}{l}\text { Pre- } \\
\text { modification } \\
\text { by } \\
\text { adjectives }\end{array}$ & 6 & 1 & 5 & 4 & 2 & 2 & & & & 1 & & 1 & 3 & 1 & 2 & 1 & & 1 \\
\hline $\begin{array}{l}\text { Pre- } \\
\text { modification } \\
\text { by nouns I }\end{array}$ & 2 & & 2 & 2 & 2 & & & & & 1 & 1 & & 8 & 4 & 4 & 2 & & 2 \\
\hline $\begin{array}{l}\text { Pre- } \\
\text { modification } \\
\text { by nouns II }\end{array}$ & & & & & & & & & & 1 & 1 & & 5 & 1 & 4 & 9 & 2 & 7 \\
\hline $\begin{array}{l}\text { Pre- } \\
\text { modification } \\
\text { by } \\
\text { adjectives + } \\
\text { nouns }\end{array}$ & 1 & 1 & & 2 & 2 & & & & & 1 & 1 & & 4 & 1 & 3 & 7 & 2 & 5 \\
\hline $\begin{array}{l}\text { Noun phrase } \\
\text { subject }\end{array}$ & 4 & 1 & 3 & & & & & & & & & & 7 & 3 & 4 & 4 & 1 & 3 \\
\hline $\begin{array}{l}\text { That-clause } \\
\text { subject }\end{array}$ & 2 & 1 & 1 & 1 & 1 & & & & & 5 & 2 & 3 & 6 & 2 & 4 & 1 & 1 & \\
\hline $\begin{array}{l}\text { Non-finite } \\
\text { clause I }\end{array}$ & 1 & 1 & & & & & & & & 1 & & 1 & 11 & 5 & 6 & 2 & 1 & 1 \\
\hline $\begin{array}{l}\text { Non-finite } \\
\text { clause II }\end{array}$ & 2 & 1 & 1 & & & & & & & 3 & 1 & 2 & 7 & & 7 & 3 & & 3 \\
\hline $\begin{array}{l}\text { Non-finite } \\
\text { clause + } \\
\text { parenthetical } \\
\text { sentence }\end{array}$ & 2 & & 2 & 1 & 1 & & & & & & & & 7 & 1 & 6 & 5 & 2 & 3 \\
\hline Total & 20 & 6 & 14 & 10 & 8 & 2 & & & & 13 & 6 & 7 & 58 & 18 & 40 & 34 & 9 & 25 \\
\hline
\end{tabular}

Table 6: Examples of comments related to the problem trigger "word order"

\begin{tabular}{|l|l|l|}
\hline Category & Participant & Comment \\
\hline $\begin{array}{l}\text { Problem } \\
\text { (P) }\end{array}$ & $\begin{array}{l}7 \text { (on non- } \\
\text { finite clause } \\
\text { II) }\end{array}$ & $\begin{array}{l}\text { "The link here was not clear to me [...] the link expressed } \\
\text { by 'troubled by'“ (translated from Palestinian Arabic). }\end{array}$ \\
\hline $\begin{array}{l}\text { Strategy } \\
\text { (S) }\end{array}$ & $\begin{array}{l}8 \text { (on pre- } \\
\text { modification } \\
\text { by } \\
\text { adjectives) }\end{array}$ & $\begin{array}{l}\text { "I kept the English word (the head noun), and when she } \\
\text { started listing bilateral, international (the adjectives) I saw } \\
\text { her slow, so I said let me memorize and not jot down. Let } \\
\text { me memorize the four words before giving- before } \\
\text { starting to translate them. In simultaneous I don't feel OK } \\
\text { when starting to write. I prefer to depend on my memory } \\
\text { rather than writing down, especially that she is saying } \\
\text { them in a clear slow way. And I said I can memorize four } \\
\text { five words" (original). }\end{array}$ \\
\hline
\end{tabular}

\subsection{Passive constructions}

Although in approximately half the cases participants did not adhere to the linguistic norms governing the use of passive constructions in Arabic, only three of them recognized the problem-trigger as such. Those three retrospective comments were only made in relation to the first passive construction that appeared in the source text. The analysis of the comments suggests that in this case the reported difficulty was not only structural, but that it also lay in finding an appropriate Arabic rendering for the verb in the passive construction. The fact that direct reference to the problem trigger has only been made in three cases indicates a low level of awareness among the students of the difficulties associated with rendering passive constructions into Arabic and the strategic competence needed to overcome those difficulties in the booth. 
Table 7: Correspondence between product and process data related to the problem trigger "passive constructions"

\begin{tabular}{|l|l|l|l|l|l|l|l|l|l|l|l|l|l|l|l|l|l|l|}
\hline & $\mathrm{P}$ & \multicolumn{1}{|c}{$\mathrm{x}$} & $\mathrm{S}$ & $\checkmark$ & $\mathrm{x}$ & $\mathrm{pS}$ & $\checkmark$ & $\mathrm{x}$ & Sat & $\checkmark$ & $\mathrm{x}$ & $\mathrm{oD}$ & $\checkmark$ & $\mathrm{x}$ & - & $\checkmark$ & $\mathrm{x}$ \\
\hline $\begin{array}{l}\text { Struct. } \\
1\end{array}$ & 3 & 0 & 3 & & & & & & & 1 & 1 & & 5 & 2 & 3 & 6 & 1 & 5 \\
\hline $\begin{array}{l}\text { Struct. } \\
2\end{array}$ & & & & & & & & & & 3 & 3 & & 9 & 4 & 5 & 3 & 1 & 2 \\
\hline $\begin{array}{l}\text { Struct. } \\
3\end{array}$ & & & & & & & & & & 1 & 1 & & 6 & 5 & 1 & 8 & 7 & 1 \\
\hline $\begin{array}{l}\text { Struct. } \\
4\end{array}$ & & & & & & & & & & & & 13 & 7 & 6 & 2 & & 2 \\
\hline $\begin{array}{l}\text { Struct. } \\
5\end{array}$ & & & & & & & & & & 2 & & 2 & 11 & 4 & 7 & 2 & 1 & 1 \\
\hline Total & $\mathbf{3}$ & $\mathbf{0}$ & $\mathbf{3}$ & $\mathbf{1}$ & $\mathbf{1}$ & & & & & $\mathbf{7}$ & $\mathbf{4}$ & $\mathbf{2}$ & $\mathbf{4 4}$ & $\mathbf{2 2}$ & $\mathbf{2 2}$ & $\mathbf{2 1}$ & $\mathbf{1 0}$ & $\mathbf{1 1}$ \\
\hline
\end{tabular}

Table 8: Example of a comment related to the problem trigger "passive constructions"

\begin{tabular}{|l|l|l|}
\hline Category & Participant & Comment \\
\hline $\begin{array}{l}\text { Problem } \\
(P)\end{array}$ & $\begin{array}{l}13 \text { (on } \\
\text { structure 1) }\end{array}$ & $\begin{array}{l}\text { "ripped apart by violence. I understand it in English, but I } \\
\text { found it difficult to say it in Arabic" (translated from Emirati } \\
\text { Arabic). }\end{array}$ \\
\hline
\end{tabular}

The category of 'satisfaction' included seven retrospective comments, two of which were inconsistent with the textual output. In the majority of cases where participants succeeded in transposing the passive into an active structure or availing themselves of other linguistic means to express passivization in Arabic, the thought process was not verbalized. In cases where the interpreting output contains prosodic features that indicate cognitive load (such as voiced hesitations or false starts), it is more likely that a conscious process had occurred that the participants were unable to recall during retrospection. If the interpretation proceeded smoothly, it is more likely that it was an automated process.

\subsection{Counter-argumentation}

Table 9: Correspondence between product and process data related to the problem trigger "counter-argumentation"

\begin{tabular}{|l|l|l|l|l|l|l|l|l|l|l|l|l|l|l|l|l|l|l|}
\hline & $\mathrm{P}$ & $\checkmark$ & $\mathrm{x}$ & $\mathrm{S}$ & $\checkmark$ & $\mathrm{x}$ & $\mathrm{pS}$ & $\checkmark$ & $\mathrm{x}$ & Sat & $\checkmark$ & $\mathrm{x}$ & $\mathrm{OD}$ & $\checkmark$ & $\mathrm{x}$ & - & $\checkmark$ & $\mathrm{x}$ \\
\hline $\begin{array}{l}\text { Struct. } \\
1\end{array}$ & 1 & & 1 & & & & & & & 2 & & 2 & 7 & 1 & 6 & 5 & 1 & 4 \\
\hline $\begin{array}{l}\text { Struct. } \\
2\end{array}$ & 1 & 1 & & & & & & & & & & 6 & & 6 & 8 & 2 & 6 \\
\hline Total & $\mathbf{2}$ & $\mathbf{2}$ & & & & & & & $\mathbf{2}$ & & $\mathbf{2}$ & $\mathbf{1 3}$ & $\mathbf{1}$ & $\mathbf{1 2}$ & $\mathbf{1 3}$ & $\mathbf{3}$ & $\mathbf{1 0}$ \\
\hline
\end{tabular}

Table 10: Example of a comment related to the problem trigger "counterargumentation"

\begin{tabular}{|l|l|l|}
\hline Category & Participant & Comment \\
\hline $\begin{array}{l}\text { Problem } \\
\text { (P) }\end{array}$ & $\begin{array}{l}\text { 3 (on } \\
\text { structure 2) }\end{array}$ & $\begin{array}{l}\text { "I remember that I felt that I wasn't able to get the details } \\
\text { of what she was saying and I was missing words" (partly } \\
\text { translated from Egyptian Arabic). }\end{array}$ \\
\hline
\end{tabular}


Out of 30 renditions of two counter-argumentative structures, 26 fell short of conveying the progression of the argument due to failure in rendering the sentence-initial signal, the contrastive shift or the propositional content of the claim and the counter-claim. Only two comments were categorized as problem segments. The vast majority of participants who did not succeed in relaying this structure into Arabic either made no comment or reported having faced other difficulties in the textual unit in question. In two cases participants expressed satisfaction, which was inconsistent with their output. The analysis of the protocols suggests that the difficulties associated with interpreting counter-argumentation into Arabic were either forgotten by the time the participants were asked to verbalize their thoughts or that the participants were not aware of their misinterpretation of the structure during the interpreting task.

\subsection{Definite article as means of emphasis}

Table 11: Correspondence between product and process data related to the problem trigger "definite article as means of emphasis"

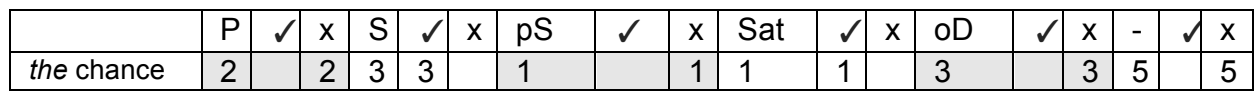

Table 12: Examples of comments related to the problem trigger "definite article as means of emphasis"

\begin{tabular}{|l|l|l|}
\hline Category & Participant & Comment \\
\hline $\begin{array}{l}\text { Problem } \\
\text { (P) }\end{array}$ & 1 & $\begin{array}{l}\text { "I thought how can I make the difference between a } \\
\text { chance and the chance?" (translated from Syrian Arabic). }\end{array}$ \\
\hline $\begin{array}{l}\text { Strategy } \\
(S)\end{array}$ & 14 & $\begin{array}{l}\text { "Then the issue with 'it is not a chance, it is the chance'. } \\
\text { So I thought how can I say that in Arabic? I said this is the } \\
\text { most important chance or something like that" (translated } \\
\text { from Saudi Arabic). }\end{array}$ \\
\hline $\begin{array}{l}\text { Potential } \\
\text { Strategy } \\
\text { (pS) }\end{array}$ & 9 & $\begin{array}{l}\text { "I just said 'chance', I didn't say the chance [...] I think it } \\
\text { should be it is not only a chance, it is the chance of } \\
\text { chances" (translated from Libyan Arabic). }\end{array}$ \\
\hline
\end{tabular}

Three participants reported conscious strategic behaviour to deal with the problem trigger which is reflected in their interpreting output. Comments were made by three participants on the problems they have encountered in dealing with the problem trigger and their inability to relay the definite article when used for emphasis into Arabic, but one of them came up with a potential strategy during the retrospection session. One participant succeeded in accentuating the significance of the chance in Arabic and expressed satisfaction with her output during retrospection. These are all cases where the retrospective comments are consistent with the textual output.

Around half the participants reported other difficulties they had faced when interpreting or did not verbalize any thoughts related to this textual unit. However, in two cases there is textual evidence of an attempt, albeit unsuccessful, to mark information saliency in Arabic. The target texts of those two participants indicate that a conscious effort had been made; however, they did not recall such cognitive processes during retrospection. 


\subsection{Modals}

Table 13: Correspondence between product and process data related to the problem trigger "modals"

\begin{tabular}{|l|l|l|l|l|l|l|l|l|l|l|l|l|l|l|l|l|l|l|l|}
\hline & $\mathrm{P}$ & $\boldsymbol{V}$ & $\mathrm{x}$ & $\mathrm{S}$ & $\boldsymbol{V}$ & $\mathrm{x}$ & $\mathrm{pS}$ & $\boldsymbol{V}$ & $\mathrm{x}$ & Sat & $\checkmark$ & $\mathrm{x}$ & $\mathrm{oD}$ & $\checkmark$ & $\mathrm{x}$ & - & $\checkmark$ & $\mathrm{x}$ \\
\hline May & & & & & & & & & & 1 & & 1 & $\mathbf{7}$ & 3 & 4 & 7 & 3 & 4 \\
\hline Might & & & & & & & & & & & & & 3 & 1 & 2 & 12 & 4 & 8 \\
\hline Have to & & & & & & & & & & & & & 1 & 1 & & 14 & & 14 \\
\hline Must & & & & & & & & & & 2 & & 2 & 4 & 1 & 3 & 9 & 8 & 1 \\
\hline Should & & & & & & & & & & & & & 4 & 2 & 2 & 11 & 5 & 6 \\
\hline Could & & & & & & & & & & & & & 2 & 1 & 1 & 13 & 5 & 8 \\
\hline Can & & & & & & & & & & 1 & 1 & & 2 & 1 & 1 & 12 & 6 & 6 \\
\hline Able to & & & & & & & & & & & & & & & & 15 & 13 & 2 \\
\hline Total & & & & & & & & & & $\mathbf{4}$ & $\mathbf{1}$ & $\mathbf{3}$ & $\mathbf{2 3}$ & $\mathbf{1 0}$ & $\mathbf{1 3}$ & $\mathbf{9 3}$ & $\mathbf{4 4}$ & $\mathbf{4 9}$ \\
\hline
\end{tabular}

In more than half of the cases, participants were not able to appropriately relay the English modal expressions into Arabic, as they either misinterpreted the type or the degree of modality. Nevertheless, there were no retrospective comments where participants acknowledged having faced problems in relaying modality or having adopted conscious strategies to appropriately render it. This suggests a relatively low level of awareness among participants of the potential pitfalls resulting from the discrepancy in the way modality is realized in both languages. Most participants either commented on other difficulties in the segment in question or did not verbalize any thoughts. In four cases, participants expressed their satisfaction with their output, but three of them were not successful in rendering the modal expressions into Arabic.

\subsection{Discourse markers}

Seven discourse markers were incorporated in the source texts. In 72 out of the 105 renditions participants failed to render the pragmatic function of the English marker into Arabic. In only five cases did the participants recognize the problem trigger as such. One participant reported facing a problem in relaying the discourse marker 'after all', which was evident in his/her target text (TT). In three cases, participants reported on strategies used to relay the markers 'still' and 'I mean'. Their TTs give evidence of the use of those strategies. Finally, one participant did not succeed in rendering the English marker and verbalized a strategy that s/he should have employed but did not. Hence, in these five cases the retrospective comments were in line with actual interpreting behaviour. The comments reflect awareness on the part of the participants of the difficulties associated with interpreting certain discourse markers. It would appear that dealing with those markers was not an automated process; rather, it required conscious cognitive effort.

Nine participants expressed their satisfaction with the way they handled the segment, including the problem-trigger. However, in seven of those nine cases participants did not succeed in correctly signalling the inter-propositional relation through the use of an appropriate discourse marker in Arabic. Thus, there is discrepancy between the retrospective comment and the actual behaviour. This indicates either that the retrieval operation was fallible or that participants were not aware of any inaccuracies at the time they were performing the interpreting task. No reference was made to difficulties in interpreting 50 instances of discourse markers, although in 40 out of the 50 cases they were not interpreted 
appropriately. Participants might have forgotten that they had faced a problem or they were not aware of the problem trigger while interpreting. In 29 out of the 41 cases where comments were categorized as 'other difficulties', the pragmatic function of the English discourse marker was not captured in Arabic. Again, this indicates that the problems either were not reflected in the protocol or have not been recognized by the participants as such during the interpreting task. As for participants who correctly relayed the discourse markers and made no direct comment on the cognitive processes that were at play during interpreting, the process of rendering them was either automated or they could not recall any conscious effort made.

Table 14: Correspondence between product and process data related to the problem trigger "discourse markers"

\begin{tabular}{|l|l|l|l|l|l|l|l|l|l|l|l|l|l|l|l|l|l|l|}
\hline & $\mathrm{P}$ & $\sqrt{ }$ & $\mathrm{x}$ & $\mathrm{S}$ & $\sqrt{ }$ & $\mathrm{x}$ & $\mathrm{pS}$ & $\boldsymbol{V}$ & $\mathrm{x}$ & Sat & $\checkmark$ & $\mathrm{x}$ & $\mathrm{oD}$ & $\checkmark$ & $\mathrm{x}$ & - & $\checkmark$ & $\mathrm{x}$ \\
\hline Indeed & & & & & & & & & & & & & & & & 15 & 1 & 14 \\
\hline Moreover & & & & & & & & & & 3 & & 3 & 3 & & 3 & 9 & 2 & 7 \\
\hline After all & 1 & & 1 & & & & 1 & & 1 & 1 & 1 & & 2 & & 2 & 10 & 3 & 7 \\
\hline No matter & & & & & & & & & & 1 & 1 & & 9 & 7 & 2 & 5 & 1 & 4 \\
\hline Still & & & & 1 & 1 & & & & & 2 & & 2 & 8 & 1 & 7 & 4 & & 4 \\
\hline Now & & & & & & & & & & 2 & & 2 & 9 & 2 & 7 & 4 & 1 & 3 \\
\hline I mean & & & & 2 & 2 & & & & & & & & 10 & 2 & 8 & 3 & 2 & 1 \\
\hline Total & $\mathbf{1}$ & & $\mathbf{1}$ & $\mathbf{3}$ & $\mathbf{3}$ & & $\mathbf{1}$ & & $\mathbf{1}$ & $\mathbf{9}$ & $\mathbf{2}$ & $\mathbf{7}$ & $\mathbf{4 1}$ & $\mathbf{1 2}$ & $\mathbf{2 9}$ & $\mathbf{5 0}$ & $\mathbf{1 0}$ & $\mathbf{4 0}$ \\
\hline
\end{tabular}

Table 15: Examples of comments related to the problem trigger "discourse markers"

\begin{tabular}{|l|l|l|}
\hline Category & Participant & Comment \\
\hline $\begin{array}{l}\text { Problem } \\
\text { (P) }\end{array}$ & $\begin{array}{l}4 \text { (on after } \\
\text { all) }\end{array}$ & $\begin{array}{l}\text { "I kept thinking 'after all', is that a conclusion? After all } \\
\text { after all. It took me quite a long time to find it (laughed). I } \\
\text { know what it means, but I didn't find something in Arabic. } \\
\text { Then I don't know what I said, I don't remember what I } \\
\text { said. But it took me some time to find 'after all'. I don't } \\
\text { know if I found it or not (translated from Moroccan Arabic). }\end{array}$ \\
\hline $\begin{array}{l}\text { Strategy } \\
\text { (S) }\end{array}$ & 8 (on still) & $\begin{array}{l}\text { "'Still' I rendered it as 'in spite of that'. I found that this is } \\
\text { what she means" (original). }\end{array}$ \\
\hline $\begin{array}{l}\text { Potential } \\
\text { Strategy } \\
\text { (pS) }\end{array}$ & $\begin{array}{l}7 \text { (on after } \\
\text { all) }\end{array}$ & $\begin{array}{l}\text { "Here when she said 'after all' I made a mistake in } \\
\text { rendering it. I interpreted it literally and then I immediately } \\
\text { thought of the alternative that I should say. I waited until } \\
\text { she completed the sentence. I shouldn't have started to } \\
\text { interpret immediately. This was a mistake" (translated from } \\
\text { Palestinian Arabic). }\end{array}$ \\
\hline
\end{tabular}

\section{Discussion}

The process data generated through retrospection yielded an insight into cognitive processes occurring in the minds of interpreting trainees from which pedagogical conclusions can be drawn. The analysis revealed a relatively low level of awareness among the participants of the difficulties associated with the different language-pair-specific problem triggers. This is evidenced by the low number of retrospective comments that fall into the category of 'problem', 'actual strategies' and 'potential strategies'. The percentage of the verbaliza- 
tions that belong to one of those three categories varied depending on the problem trigger as follows: $38.6 \%$ for acronyms, $33.3 \%$ for the definite article as means of emphasis, $22.2 \%$ for word order, $6.6 \%$ for counter-argumentation, $5.3 \%$ for passive constructions, $4.7 \%$ for discourse markers and $0 \%$ for modality. This stresses the need for pedagogical practices aimed at familiarizing students with the linguistic disparities between source and target language that might encumber their performance in the booth. This will enable them to recognize a language-pair-specific problem trigger as such and pay heed to the textual cues that signal language-pair-specific problem triggers during interpreting.

In some of the verbalizations categorized as 'problem segments' participants did not only report on having encountered a problem, but they also described the nature of the problem. This can help instructors gain a better understanding of the specific aspects of the problem trigger with which students find it difficult to deal and can thus respond to their specific needs with appropriate teaching practices. Similarly, in the category of 'actual strategies' some participants did not only state the strategies that they employed, but reconstructed the thought process that led them to the adoption of such strategies. By conducting this type of study, educators can be offered an insight into the decision-making mechanisms at play and how different factors are weighed up by students. This knowledge base can be used to guide students to make swift decisions that save them time and processing capacity; in other words, to make their decision making process more efficient. The retrospective protocols have shown that in many cases students do not consciously adopt strategies to overcome linguistic difficulties. Targeted exercises need to be designed for students to develop the necessary strategic behaviour to deal with the problem triggers, with the ultimate aim of automating this behaviour over time.

In some cases, it might seem that retrospection has raised more questions than answers it has provided. It is, for instance, unclear whether not making any direct reference to the problem trigger while succeeding in relaying it is attributable to the fact that the process was automated or the inability to recall conscious thoughts due to the time delay. It is equally unclear whether participants who failed to correctly render the problem trigger and did not address it in their verbalizations forgot about having faced difficulties by the time they were asked to articulate their thoughts or were not aware of the problem at the time of interpreting. These open questions are not to be regarded as drawbacks of the method. On the contrary, as pointed out by Kohn \& Kalina (1996), they can "lead to the establishment and investigation of more differentiated hypotheses" (p. 133).

The comparison of the data from the retrospective protocols and the actual interpreting output was used as an evaluation tool for the veridicality of the participants' reports. Although cases of correspondence between the reports and the output were frequently observed in the data, there were also instances of inconsistency between the verbalizations and the actual interpreting behaviour, which is to be expected. They include cases of participants reporting having employed a strategy while no textual evidence was found, participants expressing satisfaction while they failed to correctly render the problem trigger, participants reporting having encountered problems while they succeeded in providing an appropriate rendering and, finally, cases where there was textual evidence of the use or attempt to use a strategy which has not been articulated by the participants. These discrepancies, however, do not constitute grounds for invalidating 
retrospection as a tool to investigate interpreting processes, precisely because they can be identified.

\section{Conclusion}

This article has attempted to shed light on the method of retrospection and its application in Interpreting Studies. The reliability of this method has been called into question due to limitations pertaining to the completeness and accuracy of the information obtained therefrom, in addition to personal and interpersonal factors that can impact the data. While concerns about the reliability of the method are justified, they do not form a reason to discard it as a tool to gain access to cognitive processes at play during simultaneous interpreting. Retrospection is best used to supply complementary data as part of a mixed-method approach. Comparing the verbalizations with product data, for instance, allows researchers to identify and exclude segments of the protocols which do not correspond to the actual interpreting behaviour.

The study presented in this article has shown that retrospective protocols can be a useful method for pedagogical purposes, which is a new line of research that merits further exploring. The information obtained from retrospection can contribute to enhancing "problem-oriented training" that "helps interpreters to recognize, separate and focus on single difficulties thus facilitating a conscious development of diversified simultaneous interpreting strategies" (Riccardi, 1996, p. 221). Arguably, retrospection is not only a valid research method, but it can be incorporated into teaching practice: instructors and students alike can benefit from reflecting on thought processes in the interpreting class. The information which can be gleaned from retrospection can contribute to process-oriented research in interpreting pedagogy. Tapping into the minds of interpreting trainees can help researchers and educators determine the factors that encumber students' performances and gain a better understanding of the development of strategic competence. More empirical research that looks at retrospection from this perspective will contribute to develop sound pedagogical tools for different language pairs.

\section{References}

Al-Qinai, J. (2007). Abbreviation and acronymy in English-Arabic translation. Meta, $52(2), 368-375$

Al-Rubai'i, A. M. H. A. (2004). The effect of word order differences on English-intoArabic simultaneous interpreters' performance. Babel, 50(3), 246-266.

Baker, M. (1992). In other words. A coursebook on translation. London: Routledge.

Bartłomiejczyk, M. (2006). Strategies of simultaneous interpreting and directionality. Interpreting, 8(2), 149-174.

Cantarino, V. (1975). Syntax of Modern Arabic prose (Vol. 1). Bloomington: Indiana University Press.

Chang, C.-c., \& Schallert, D. L. (2007). The impact of directionality on Chinese/English simultaneous interpreting. Interpreting, 9(2), 137-176.

Damasio, A. (1994). Decartes' error: Emotion, reason and the human brain. New York: Grosset/Putnam.

Dimitrova, B. E., \& Tiselius, E. (2009). Exploring retrospection as a research method for studying the translation process and the interpreting process. In I. M. Mees, F. Alves \& S. Gopferich (Eds.), Methodology, technology and innovation in translation process research: a tribute to Arnt Lykke Jakobsen (Vol. 28, pp. 109134). Frederiksberg: Samfundslitteratur. 
Donato, V. (2003). Strategies adopted by student interpreters in SI: A comparison between the English-Italian and the German-Italian language-pairs. The Interpreters' Newsletter(12), 101-134.

Eades, D. (2011). Translating English modal expressions. An Arab translator trainee's perspective. Babel, 57(3), 283-304.

Ericsson, K. A., \& Simon, H. A. (1987). Verbal reports on thinking. In C. Færch \& G. Kasper (Eds.), Introspection in second language research (Vol. 24-53). Clevedon/Philadelphia: Multilingual Matters.

Ericsson, K. A., \& Simon, H. A. (1993). Protocol Analysis: Verbal reports as data (Revised Edition). Cambridge, Massachusetts/London, England: The MIT Press.

Færch, C., \& Kasper, G. (1987). From product to process - Introspective methods in second language research. In C. Færch \& G. Kasper (Eds.), Introspection in Second Language Research (pp. 5-23). Clevedon/Philadelphia: Multilingual Matters.

Gavioli, L., \& Mansfield, G. (Eds.) (1990). The PIXI corpora. Bologna: Cooperativa Libraria Universitaria Editrice.

Gerver, D. (1971). Aspects of simultaneous interpretation and human information processing. Oxford: Oxford University Press.

Gile, D. (1995/2009). Basic concepts and models for interpreter and translator training (Revised Edition). Amsterdam/Philadelphia: John Benjamins.

Halliday, M. A. K., \& Hasan, R. (1976). Cohesion in English. London / New York: Longman.

Hansen, G. (2005). Experience and emotion in empirical translation research with think-aloud and retrospection. Meta, 50(2), 511-521.

Hatim, B. (1997). English-Arabic/Arabic-English translation. A practical guide. London: Saqi Books.

Hawas, H. M. (1989). The articles in English and Arabic: A contrastive study. Indian Journal of Applied Linguistics, 15(2), 23-51.

Ivanova, A. (1999). Discourse processing during simultaneous interpreting: An expertise approach. Cambridge: University of Cambridge Press

Ivanova, A. (2000). The use of retrospection in research on simultaneous interpreting. In S. Tirkkonen-Condit \& R. Jääskeläinen (Eds.), Tapping and mapping the process of translation and interpreting (pp. 27-52). Amsterdam/Philadelphia: John Benjamins.

Jääskeläinen, R. (2002). Think-aloud protocol studies into translation. An annotated bibliography. Target, 14(1), 107-136.

Khalil, A. (1993). Arabic translation of English passive sentences: Problems and acceptability judgements. Papers and Studies in Contrastive Linuistics, 27(169181).

Kohn, K., \& Kalina, S. (1996). The strategic dimension of interpreting. Meta, 41(1), 118-138.

Krings, H. P. (1987). The use of introspective data in translation. In C. Færch \& G. Kasper (Eds.), Introspection in second language research (pp. 159-176). Clevedon/Philadelphia: Multilingual Matters.

Kurz, I. (1983). 'Der von uns..': Schwierigkeiten des Simultandolmetschens DeutschEnglisch. In Festschrift zum 40 Jährigen Bestehen des Instituts für Übersetzerund Dolmetscherausbildung der Universität Wien (pp. 91-98). Tulln: Ott Verlag.

Lapadat, J. C. (2000). Problematizing transcription: purpose, paradigm and quality. International Journal of Social Research Methodology, 3(3), 203-219.

Mann, S. (1982). Verbal reports as data: A focus on retrospection. In F. Katamba, S. Dingwall \& S. Mann (Eds.), Methods and problems in doing applied linguistic research (pp. 87-104). Lancaster: Department of Linguistics and Modern English Language, University of Lancaster.

Merten, K. (1983). Inhaltsanalyse. Einführung in Theorie, Methode und Praxis. Opladen: Westdeutscher Verlag.

Napier, J. (2004). Interpreting omissions: A new perspective. Interpreting, 6(2), 117142.

Niemants, N. S. A. (2012). The transcription of interpreting data. Interpreting, 14(2), 165-191. 
Ribas, M. A. (2012). Problems and strategies in consecutive interpreting: A pilot study at two different stages of interpreter training. Meta, 57(3), 812-835.

Riccardi, A. (1996). Language-specific strategies in simultaneous interpreting. In C. Dollerup \& V. Appel (Eds.), Teaching translation and interpreting 3 (pp. 213222). Amsterdam/Philadelphia: Benjamins.

Ross, D. M. (1997). La struttura linguistica e l'elaborazione sintattica: strategie generali e specifiche. In L. Gran \& A. Riccardi (Eds.), Nuovi orientamenti negli studi sull'interpretazione (pp. 91-109). Trieste: SSLMIT.

Seeber, K. (2013). Cognitive load in simultaneous interpreting. Measures and methods. Target, 25(1), 18-32.

Shakir, A., \& Farghal, M. (1997). When the focus of the text is blurred: A textlinguistic approach for analyzing atudent interpreters' errors. Meta, 42, 629640 .

Shlesinger, M. (1995). Shifts in cohesion in simultaneous interpreting. The Translator, $1,193-214$.

Shlesinger, M. (2000). Interpreting as a cognitive process: How can we know what happens? In S. Trikkonen-Condit \& R. Jääskeläinen (Eds.), Tapping and mapping the processes of translation and interpreting (pp. 3-15). Amsterdam: John Benjamins.

Straniero Sergio, F. (1999). The interpreter on the (talk) show: Interaction and participation frameworks. The Translator, 5(2), 303-326.

Szakos, J., \& Glavitsch, U. (2004). Portability, modularity and seamless speechcorpus indexing and retrieval: A new software for documenting (not only) the endangered Formosan Aboriginal languages. Paper presented at the E-MELD Language Digitization Project Conference, Worshop on Lingusitic Databases and Best Practice. Retrieved from http://emeld.org/workshop/2004/szakospaper.html

Tiselius, E., \& Jenset, G. B. (2011). Process and product in simultaneous interpreting. What they tell us about experience and expertise. In C. Alvstad, A. Hild \& E. Tiselius (Eds.), Methods and strategies of process research. Integrative approaches in Translation Studies (pp. 269-300). Amsterdam/Philadelphia: John Benjamins.

Titscher, S., Meyer, M., Wodak, R., \& Vetter, E. (2000). Methods of text and discourse analysis (B. Jenner, Trans.). London: Sage Publications.

Uchiyama, H. (1991). Problems caused by word order when interpreting / translating from English into Japanese: The effect of the use of inanimate subjects in English. Meta, 36(2-3), 404-413.

Vik-Tuovinen, G.-V. (2002). Retrospection as a method of studying the process of simultaneous interpreting. In G. Garzone \& M. Viezzi (Eds.), Interpreting in the 21 st century. Challenges and opportunities. Selected papers from the 1st Forli Conference on Interpreting Studies, 9-11 November 2000 (pp. 63-71). Amserdam/Philadelphia: John Benjamins. 